Article

\title{
Concerns and Opportunities around Cultural Heritage in East Asian Globally Important Agricultural Heritage Systems (GIAHS)
}

\author{
Hiroyuki Kajihara ${ }^{1}$, Su Zhang ${ }^{2, *}$, Wonhee You ${ }^{3}$ and Qingwen Min ${ }^{2, *}$ \\ 1 Mount Aso Ecomusée, Kumamoto 8691505, Japan; tanibito@yahoo.com \\ 2 Institute of Geographic Sciences and Natural Resources Research, Chinese Academy of Sciences, \\ Beijing 100101, China \\ 3 Research Institute for Regional Government and Economy, Jeju 63139, Korea; kaniwonyou@naver.com \\ * Correspondence: zhangsu.work@gmail.com (S.Z.); minqw@igsnrr.ac.cn (Q.M.); \\ Tel.: +86-010-6488-9007 (Q.M.)
}

Received: 25 December 2017; Accepted: 5 April 2018; Published: 18 April 2018

\begin{abstract}
Fifteen years have passed since Food and Agriculture Organization (FAO) launched the Globally Important Agricultural Heritage Systems (GIAHS) project in 2002. In this time, participation from East Asian countries has been increasing rapidly with interest flowing over into several related subjects and disciplines. Culture is one of the selection criteria that has to be satisfied to become a GIAHS site, and equally culture plays an important role in the development of tourism to a destination. However, few scientists or GIAHS members have discussed directly how to apply cultural features in GIAHS. Therefore, the purposes of this paper are firstly to recognize the importance and contribution of culture in GIAHS. Then, through detailing the current forms of cultural management in the GIAHS located in Japan, Korea, and China, we identify some of the key cultural problems and prospects in those sites. Two social surveys conducted in Japan show that culture is a prime motivation for tourist visitation, as well as being a core GIAHS selection criteria. These surveys further highlight that GIAHS needs to incorporate culture more effectively into their management strategies. Detailed descriptions of the three countries analyzed in this paper outline each has to engage with particular cultural management challenges: Japan has a well-arranged list of cultural assets, but is unclear how to move forward with that information and data. Korea has just begun to generate a strategy on how to manage cultural heritage features in GIAHS with the use of approaches such as Agrostories or Gil tourism, in recognition of the gradual changes that are occurring in local identity. China has the longest history of engagement with GIAHS in the East Asia region. However, the utilization of the model here has recognized further issues of change in cultural identity not least through commercialization. This paper therefore identifies, discusses and arranges eight problems and prospects for collaborative research on aspects of cultural management amongst the GIAHS in East Asia.
\end{abstract}

Keywords: Globally Important Agricultural Heritage System (GIAHS); Food and Agriculture Organization (FAO); culture; East Asia; tourism; Agrostory; Intangible Cultural Heritage (ICH); intangible cultural property; globalization; commercialization; identity change

\section{Introduction}

\subsection{GIAHS and Culture}

It is over a decade since we had the first Globally Important Agricultural Heritage System (GIAHS) site in East Asia. The program began in 2002 by Food and Agriculture Organization (FAO) of the 
United Nations to safeguard and support the world's agri-cultural heritage systems, and was initially given a primary focus on cases in developing countries. Currently, the Asia and Pacific region has become the largest participant in the GIAHS network encompassing more than $68 \%$ of the world's 44 sites: three being situated in Africa, 30 in Asia and the Pacific, two in Europe and Central Asia, three in Latin America and the Caribbean, and six in the Near East and North Africa [1]. Especially East Asian scientists and local government officers of China, Japan and Korea have organized since 2013 their own transnational academic society in the form of the East Asia Research Association for Agricultural Heritage Systems (ERAHS): This structure organized its first conference in Xinghua, China, during April 2014; the second conference then took place in Sado, Japan, June 2015; the third was in Geumsan, Korea, June 2016; the fourth was in Huzhou, China, July 2017; and the fifth will be in Minabe and Tanabe, Japan, August 2018. The number of participants is increasing and the topics discussed in the sessions are also expanding year by year.

Although culture is one of the five GIAHS criteria as "Cultures, Value Systems and Social Organizations" [2], few approaches considering culture directly have arisen in discussions so far. This we believe is derived from the demographic of the academy of GIAHS consisting mainly of natural or social scientists, with few human scientists as yet directly involved. Hence, the objectives of this paper are to recognize the role of culture in GIAHS, describe how each GIAHS in Japan, Korea, and China is currently managing its cultural assets, and draw out our common cultural prospects for the near future. This is the first transnational paper regarding culture in GIAHS, and has emerged following discussions during the fourth ERAHS conference in China.

\subsection{Cultural Contribution to GIAHS}

Currently, FAO has not provided any strict definitions regarding culture in GIAHS and how it may be utilized. They just state that cultural identity and a sense of place are embedded in and belong to specific agricultural sites, and show ceremonial, religious and/or spiritual experiences as the form social organizations and practices may take [3]. However, we can notice they refer to some "experiences" concretely, therefore we may say GIAHS is looking upon culture importantly as an intangible value rather than a tangible one. Hence, the definition of Intangible Cultural Heritage (ICH) by UNESCO may help and support our position in the discussions found in this paper. UNESCO states that Cultural Heritage also includes traditions or living expressions inherited from our ancestors and passed on to our descendants, such as oral traditions, performing arts, social practices, rituals, festive events, knowledge and practices concerning nature and the universe or the knowledge and skills to produce traditional crafts [4]. In this paper, we will follow this UNESCO definition basically to discuss culture in GIAHS.

On the other hand, FAO states that one of the goals of the program is to identify and safeguard GIAHS, with (eco)tourism offered as an example of how to generate income and add economic value to goods and services of each system [3]. Indeed, tourism is an effective means for sustaining the program and culture plays an important role in shaping such forms of tourism. Figure 1 presents the results of a survey for tourists and shows the type of activities that motivate foreign tourists who visited Japan in 2014 [5]. This is a survey by Japan Tourism Marketing Cooperation: Male 56\%, female $44 \%(n=322)$; Under teenagers $6 \%$, 20's $15 \%, 30$ 's $15 \%$, 40's $19 \%$, 50's $19 \%$, more than 60 's $26 \%$ ( $n=325)$; They came from US 27\%, OZ 13\%, UK 6\%, Canada 6\%, Indonesia 5\%, Singapore 5\%, Malaysia 4\%, France 3\%, Italy 3\%, Swiss 3\% $(n=321)$; from February 6 to March 10 of 2014.

Two things we may say from the survey results shown in Figure 1: that GIAHS can cover almost all of the answers among these top ten, and culture is the most attractive element for visitors (encompassing the 1st, 3rd, 4th, 6th, 7th, and 9th ranked answers). In other words, researching culture may enhance the GIAHS program, by leading to stronger economic recovery for the sustainable development of the local communities. We can also verify such tendencies indicated in the survey, through analyzing posts on the further analysis of social media (Figures 2 and 3). 


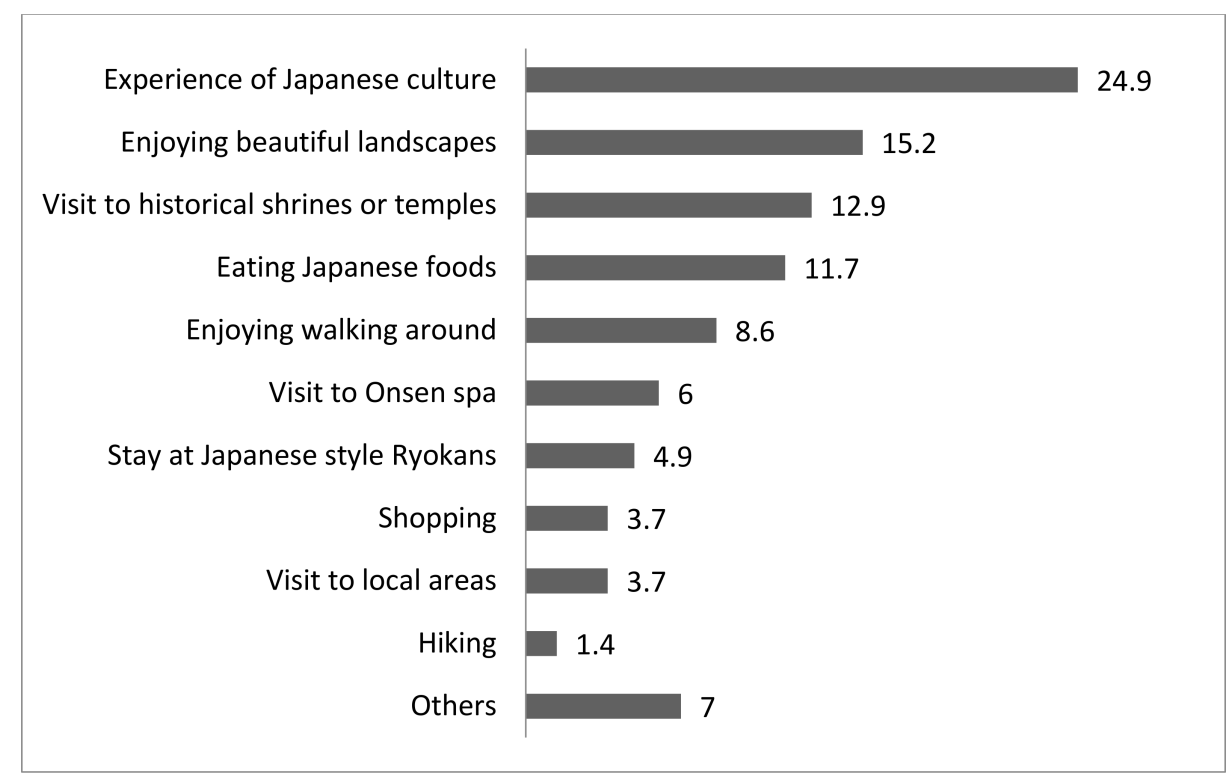

Figure 1. The most interested activities in Japan for foreign tourists $(n=349)$.
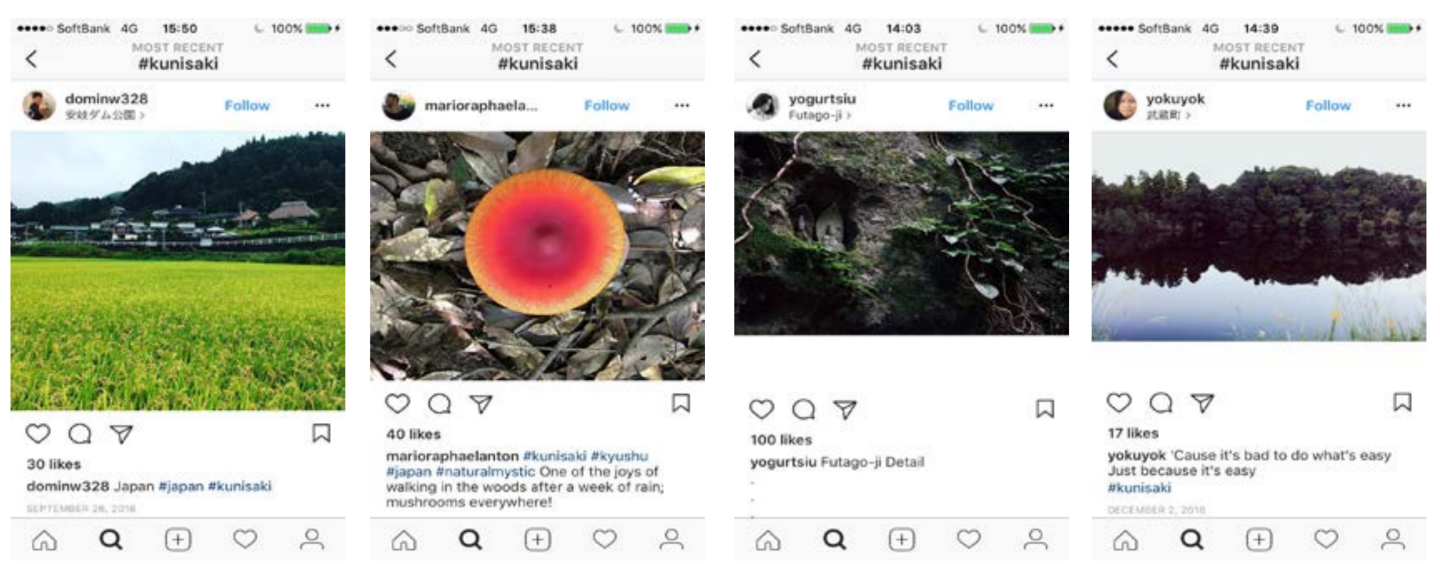

Figure 2. Posts to Instagram on GIAHS criteria with the \#Kunisaki tag (2017).

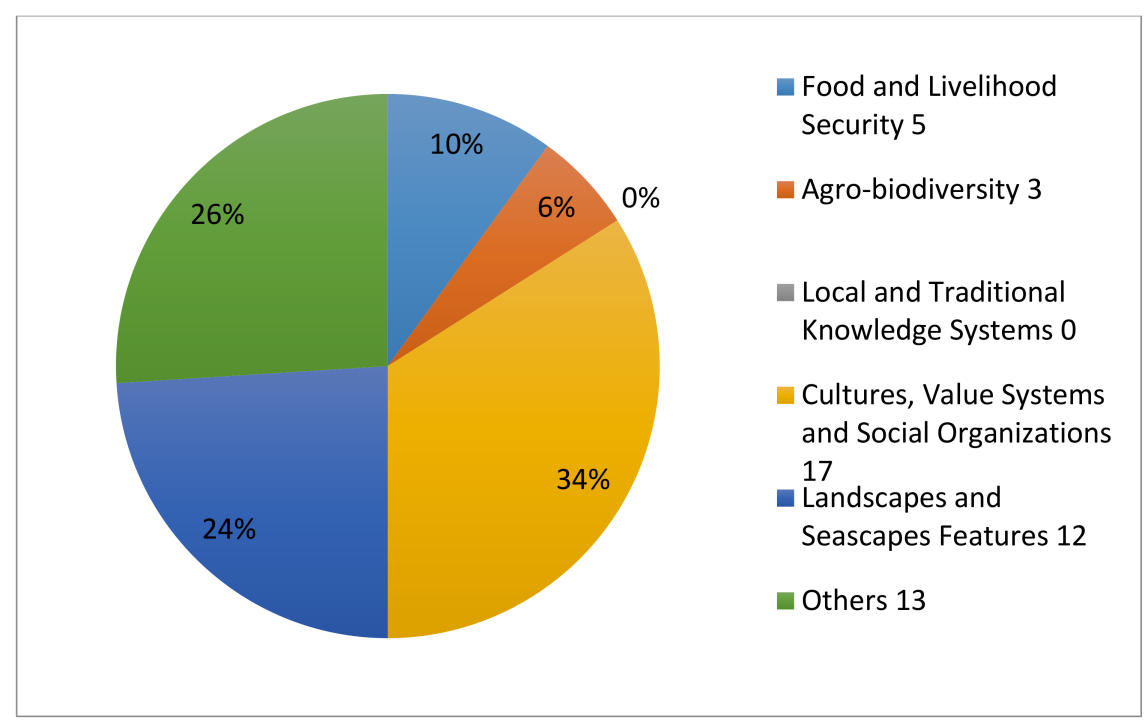

Figure 3. Contribution towards GIAHS criteria. 
When foreign tourists visit a place, they are willing to take a picture of what they were inspired by, and to upload those responses to the Internet to share their experiences with their friends. Therefore, if you analyze their posts, you may grasp what they were actually interested in the region. Figures 2 and 3 are the results of a survey to analyze posts to Instagram uploaded by foreign visitors who visited Kunisaki Peninsula Usa GIAHS site in Japan. This survey was taken place in February of 2017; Among 50 samples, 11 of Indonesian, 5 of Korean, 4 of Hongkongese, 2 of UK, 2 of Singaporean, 2 of Thai, 1 of US, 1 of Vietnamese, 1 of Vietnamese Australian, 13 of Westerners who married Japanese women, 6 of Asian living in Japan, 2 of Japanese descent (American, Danish). Figure 2 shows some concrete samples of, from left to right, "Food and Livelihood", "Agro-biodiversity", "Culture, Value Systems and Social Organizations", and "Landscapes and Seascapes Features". Fifty posts with the tag \#kunisaki were collected (29 males, 21 females) and classified into five GIAHS criteria. Figure 3 shows that culture has the largest contribution to GIAHS in motivating foreign visitors $(34 \%)$, and unfortunately "Local and Traditional Knowledge Systems" does not come into the sight of foreign visitors at all $(0 \%)$. Although these surveys can expose latent demands for the strategy of GIAHS, space does not permit us to discuss these factors more deeply in this paper. Here, we just wish to point out that the results in Figure 3 support our argument of the survey summarized in Figure 1, that we should deal with culture much more adequately in the development and management of GIAHS.

\section{Cultural Management in Japan}

\subsection{Cultural Problems in Japanese GIAHS}

As of November 2017, Japan has eight GIAHS sites. The first two sites were designated in 2011. After that, new sites were added every two years; three in 2013 and three in 2015. As already mentioned in Section 1.2, each GIAHS site must show the five criteria including culture. Table 1 shows National Cultural Properties of Japan and UNESCO ICH, including other local properties in Japanese GIAHS for now.

The first column of Table 1 shows the titles of GIAHS sites and the year when they were designated as GIAHS. The second column shows cultural properties in the regions that we can recognize in the list of Important Intangible Folk-cultural Properties of Japan (IIFP*), the website of the Ministry of Agriculture, Forestry and Fisheries of Japan (MAFF), and each official GIAHS site, or the list of UNESCO Intangible Cultural Heritage $\left(\mathrm{ICH}^{* *}\right)$ in addition to the year when they were designated. Moreover, local cultures that each GIAHS introduces on their websites are also included. Table 1 presents information from different lists, hence it does not mean that each GIAHS site presents and explains all the cultural elements on their websites, rather they just introduce them. In the overviewing Table 1 and each GIAHS website, we may divide them into three groups: Sites never referring to the specific cultural properties (Sado, Shizuoka [6], Minabe [7], and Takachiho [8]); Sites showing just a few names of cultural properties (Noto [9] and Kunisaki [10]); and Sites mentioning a few prominent cultural properties with a brief introduction (Aso [11] and Nagara [12]) (Sado GIAHS doesn't have their own website). There may be two reasons for this: no space to explain in detail, and/or no interest in culture despite the abundant cultural expressions they hold. Importantly, up until now, culture seems just to represent additional information for the Japanese GIAHS. Moreover, we should consider whether we should expand the concept of culture, not only in the designated properties shown in Table 1 but also in common intangible cultures such as our memories or soundscapes. This is because explanations are not offered as to why the cultural component is of particular significance in relation to the GIAHS or how they may be integrated into its development. 
Table 1. Cultural elements in Japanese GIAHS.

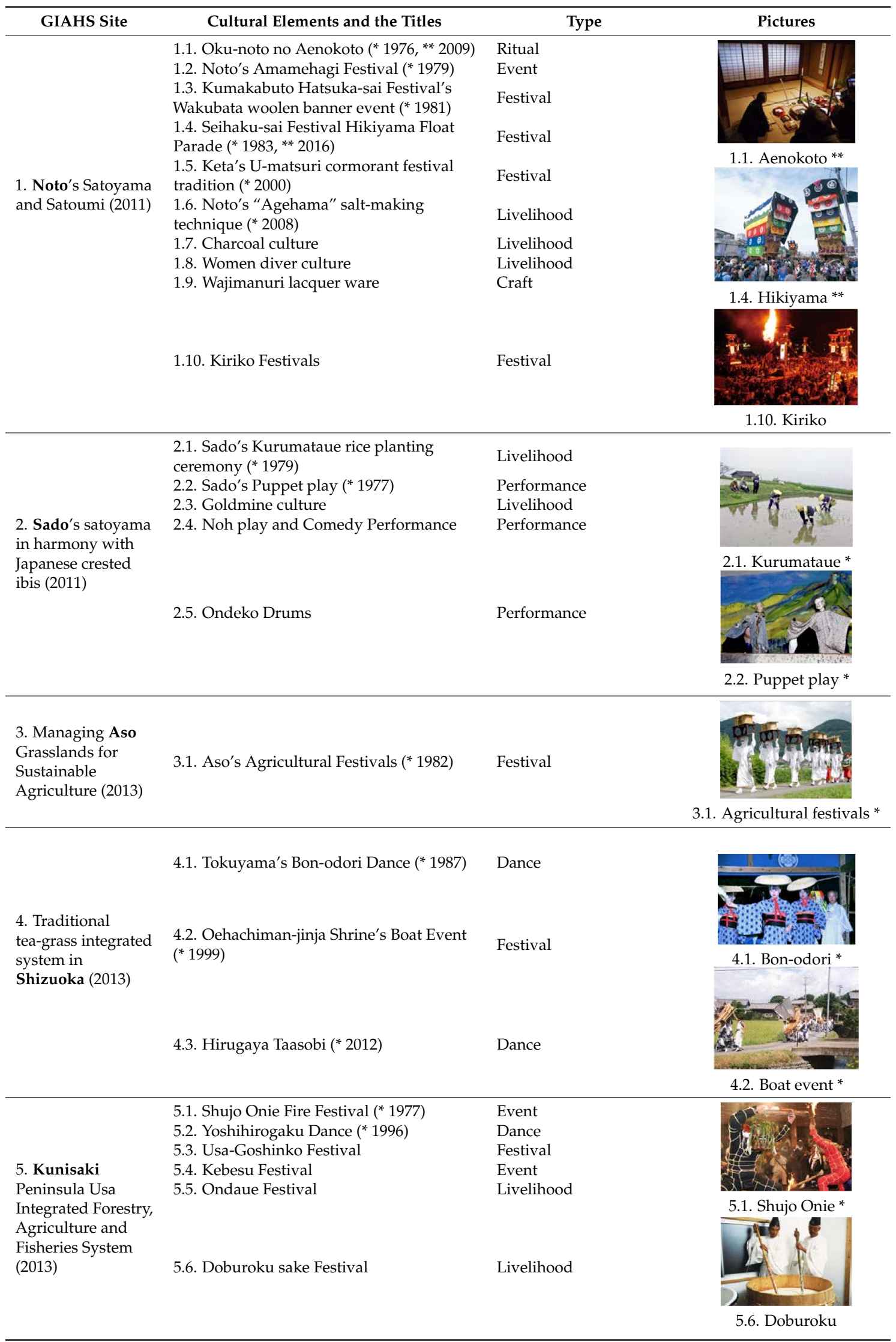


Table 1. Cont.

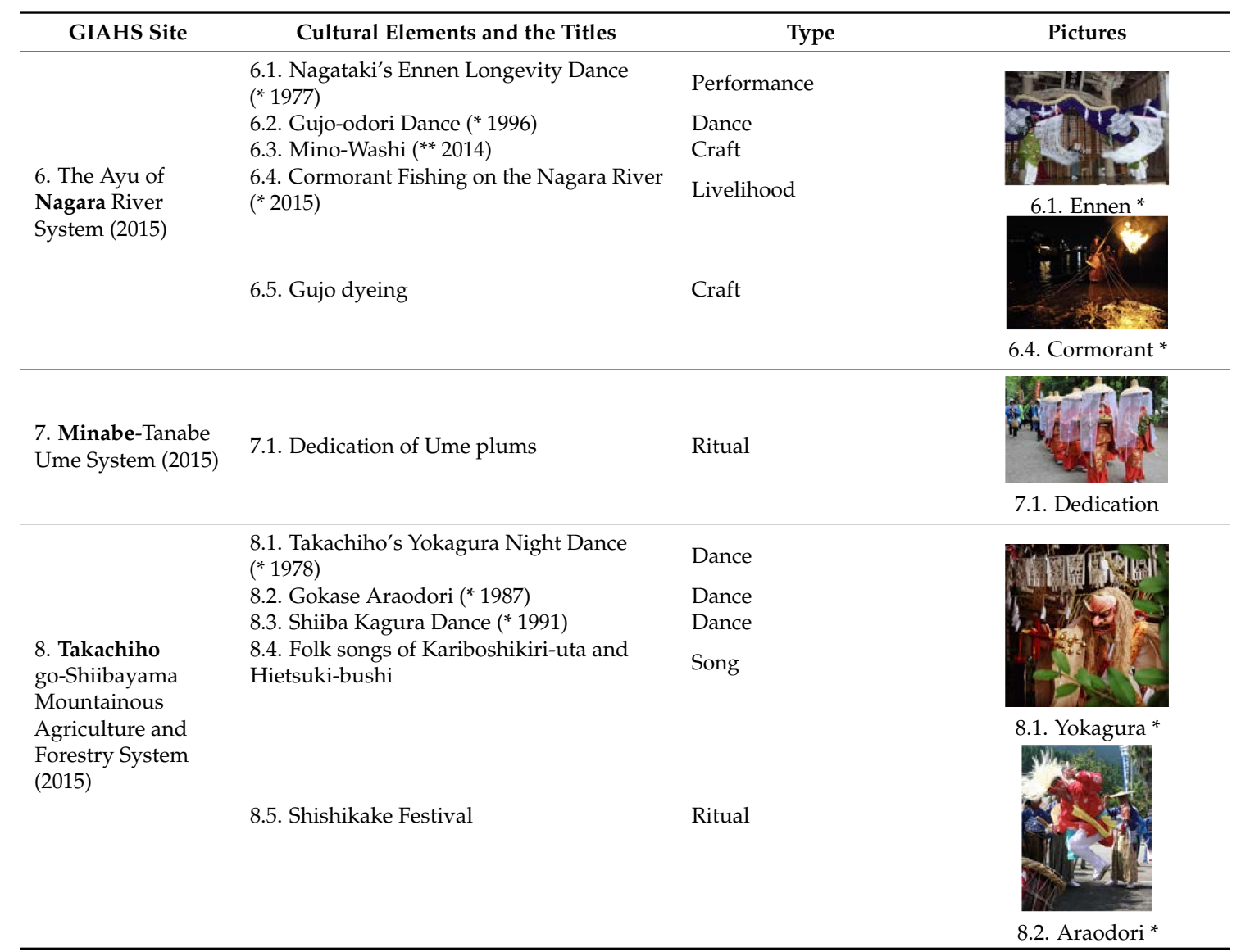

Notes: The boldface shows the first name of the place in GIAHS site. All pictures are from the websites of each GIAHS site, of local city governments, or the database of The Agency for Cultural Affairs of Japan. * Important Intangible Folk-cultural Properties of Japan; ** UNESCO Intangible Cultural Heritages (ICH); no years and asterisks are other local cultural properties that the GIAHS introduces on the website.

\subsection{From a List of Cultures to Agro-Stories}

GIAHS, of course, is not the solitary system through which to introduce culture or represent cultural features. We have to utilize culture in the wider context of GIAHS and try to explain agriculture. Otherwise, GIAHS does not show how it works alongside other criteria of the agricultural system, such as land resource management or biodiversity. Why then have certain discussions regarding culture in GIAHS taken place? At first, the GIAHS program was launched mainly by agricultural scientists and governmental officers of the agricultural sector; obviously, cultural experts operating in this sector are in short supply. Little thought was subsequently offered to bring in professionals with specific cultural expertise. To make culture work in GIAHS, cultural scientists are required to explain how cultural elements contribute to the working of GIAHS. Furthermore, input from cultural specialists would be needed if sites really expect to see the benefits mentioned in Section 1.2, such as tourism, strengthening community identity, or improved social relationships being realized.

Another reason, related to the one stated above, is that the relationship between local agriculture and culture cannot be seen clearly through in their explanations. Although they helpfully try to show a list of cultural expressions, they often cease explaining in more detail this selection, leading instead to a descriptive naming exercise where no effort is provided to contextualize.

Then, how can we deal with culture in GIAHS? In responding to this question, a Geopark, a similar program of UNESCO, can give us a possible solution. Geoparks derive from actions taken by the related UNESCO program, that is the Global Geoparks Network (GGN). Geoparks have also had issues such as how to deal with culture in their sites [13]. The Geopark network and model also draws 
from a lot of contributions by natural scientists, especially geologists. Similar to the GIAHS society, some of those contributions insisted that the Geopark model does not need to address cultural issues or focus upon cultural heritage features (especially, I've heard that in some international conferences, a few European scientists felt resistance to dealing with culture in Geoparks). However, especially Japanese scientists have insisted strongly that the human relationship is also needed in a Geopark (Since Japanese Geoparks have a lot of such problems of disaster especially, they surely needed to consider not only nature but human concern. Holding a symposium of disaster and Geoparks in the UNESCO conference in Nagasaki, Japan in 2012, would become a turning point for them). Consequently, the European Geoparks Network (EGN) now also recognizes the value and significance of culture in a Geopark and its contribution towards sustaining Geotourism initiatives. For instance, it describes on its official website that "The majority of sites present on the territory of a European Geopark must be part of the geological heritage, but their interest may also be archaeological, ecological, historical or cultural" [14].

A similar challenge was also faced in the usage of Geotourism that, through a narrow definition, encourages the promotion and acknowledgement of geological heritage. In so doing, it has been observed that visitors struggle to grasp the purely scientific values and repeat visitation is limited. Hence, they have changed the strategy from just counting the heritage sites in isolation, to connecting those different heritage components into a more complete and significant story. They advocated it as a method that has been described and promoted as an earth story or "Geostory" [15]. For instance, in 2015-2016, some young Japanese scientists have issued a series of four books of such Geostories [16]. People visiting a Geopark can then better understand the geological values through the Geostories, since they can feel sympathy for the eloquent human dramas, even though it is hard for quiet stones. The GIAHS society can also adapt those movements into the tourism initiatives. If they can show not only a list of culture but also the relationship between heritages including natural and cultural as a sequential story, then visitors should be able to understand the field much more deeply. It may be possible therefore to advocate and promote for instance an equivalent Agro-Story or Agrostories.

\section{Cultural Management in Korea}

\subsection{Cultural Background of Korean GIAHS}

The history of Korean GIAHS is not long. In 2014, the first KIAHS, Korean Important Agricultural Heritage System, of Cheongsando Gudeuljangnon as "Flat Stone Floor Paddy Field System" in Wando Island, Jeollanamdo Province, and the second KIAHS of Jeju Batdam as "Stone Fence Agricultural System in Jeju Island" were designated as first Korean GIAHS sites by FAO. Subsequently, the "Traditional Hadong Tea Agrosystem, Hwagae-myeon" was also designated as the third Korean GIAHS site in 2017. In Korea, KIAHS is managed and designated by MAFRA (Ministry of Agriculture, Food and Rural Affairs) of Korea [17]. The first two designated GIAHS sites of the Islands of Cheongsando and Jeju are both located off the southern part of Korea in the Korean Peninsula. In relying on reasons why those two islands were designated, we can find the culture and history inherent in Korea. Gudeul means the typical Korean cultural expression of Ondol, the underfloor house-heating system, and Batdam in Jeju Island is also called Heuknyong-malli, meaning the longest black dragon. Moreover, Jeju Island has been acknowledged as the site for a set of outstanding natural and cultural landscapes, resulting in further global designations, including UNESCO Biosphere Reserve (2002), UNESCO Jeju World Natural Heritage (2007), UNESCO Intangible Cultural Heritage of Humanity: Jeju Chilmeoridanggut (2009), UNESCO Jeju Island Global Geopark (2010), UNESCO Intangible Cultural Heritage of Humanity: Jeju HaenyeoCulture (2016) and FAO GIAHS Jeju Batdam Agricultural System (2014).

About 2.77 million people, or $5.5 \%$ of the total Korean population, depend on farming and their staple food is rice. Rice provides the greatest income within the Korean farming structure, contributing around $20 \%$ overall according to the survey conducted by Ministry of Government Administration and 
Home Affairs of Korea in October 2017. Korean agriculture can be separated into rice paddy farming and dry-field farming. As of 2017, KIAHS sites of the rice paddy farming system include "The terrace paddy fields, reservoirs, puddles and irrigation ditches", and of the dry-field farming system includes "The Batdam Agricultural System", "Terrace Tea Plantation", "Sansuyu (Cornus officinalis) System", "Ginseng Agricultural System" and "The Bamboo Forest System". The cultivation of rice in Korea stretches back over 2500 years ago, with rice seeds aged from 12,500 to 13,920 years ago being discovered, thus indicating the origination of Domesticated Rice in the Korean Peninsula.

\subsection{Cheongsando Gudeuljangnon and Jeju Batdam Agricultural System}

Cheongsando Gudeuljangnon (Flat Stone Floor Paddy Field) System in Wando Island, Jeollanamdo Province is the utilization of a similar traditional system of the traditional Ondol floor heating system which is utilized to even support rice cultivation, and overcome the given disadvantageous natural environment. Ondol is the typical Korean culture of the underfloor house-heating system to keep the floor warm by blowing heated air from the kitchen (Figure 4a). In Cheongsando, the irrigation structure is built by placing the water path in the pebble layer under the Gudeuljang floor just like Ondol. Then, the system is covered with mud and soil to manage the water retention level and temperature controlling. The irrigation water flows under the fields, as heated air flows under the floor in an Ondol house. "Gudeuljang" means stone layers of Ondol and "-non" means rice fields in Korean. The uniqueness of Gudeuljangnon is the stone built lower part, showing the collaborations among the Korean traditional and cultural Ondol floor system for dwellings and agricultural irrigation system. With the system, the land use level was maximized and any lands in the island could be utilized either for rice paddy or dry field farming by water level management. The significance of the system is that the continuous-flow irrigation system of the rice paddy has developed through the water passing from the top down then to the lower part of a circulation system. The system has served its role as the function in eco-corridors, providing soundscapes for irrigation water which allows various species by connecting nearby forests and rice paddies.

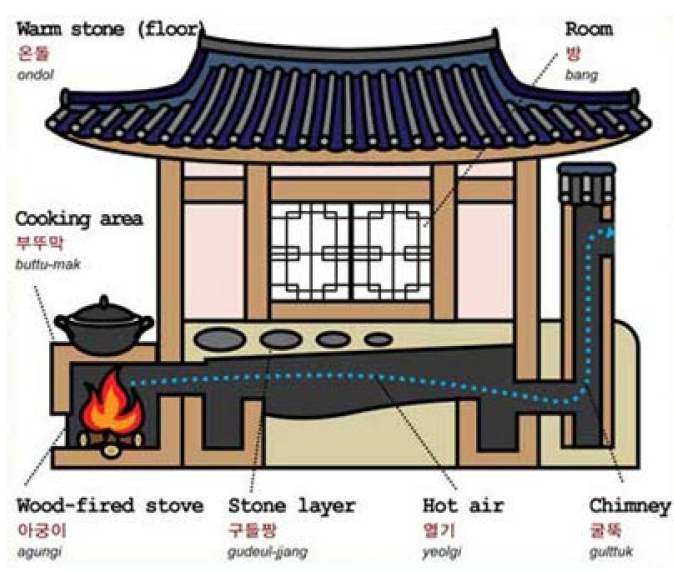

(a)

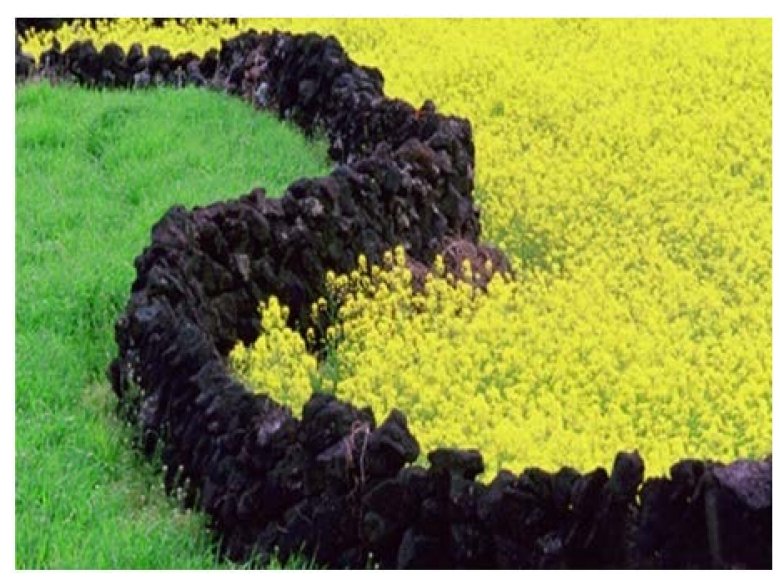

(b)

Figure 4. Korean Ondol (a) [18]; and Batdam as the black dragon (b).

The second KIAHS of Jeju Batdam (Stone Fence) Agricultural System includes the 22,000 km long stone fence structure around most dry fields on the island (Figure $4 \mathrm{~b}$ ). The volcanic Jeju Island has been culturally known as "The Island of three abundances and three non-existences" [19]. The three abundances of Jeju mean women, wind and rocks, while three non-existences are believed as no thieves, no gates and no beggars. Most of the soil of Jeju Island is covered with basalt rocks with the highest degree of water permeability. In turn, this means the land conditions are unsuitable for 
ordinary farming. The average depth of cultivated soil is shallow at about $18.3 \mathrm{~cm}$, and up to $40 \%$ of the soil is filled with pebbles. As a result, the barren environment has not been generous for either people or farming for food security and supply, with productivity further impacted by the incoming harsh winds that persist all year around. During the Joseon Dynasty, Jeju Island had used as a site to relocate political exiles due to its remoteness and inaccessible location and this led to the birth of Batdam Agricultural System of Jeju. As the entire Jeju Island has been covered with volcanic rocks, people had to remove the pebbles and rocks out of their lots to produce vegetables. The high draining feature of the island soil made farming most difficult. The strong winds kept knocking down crops even before their rooting takes part. Therefore, the forefathers started to utilize the rocks and pebbles in their lots which they had to remove. Then, with this resource, they built walls around their small pieces of land to soften the winds and act as windbreaks to prevent further soil losses, retain the moisture and increase the temperature of the areas, in addition to block off trespassing by horses and cattle. In addition, the wall also functioned as the primary indicator of the property boundary.

With little arable land available, ancestors of Jeju Island had to create a different culture of inheriting to the custom expressed on the Korean Peninsula. Most Korean assets were usually passed down only to the oldest son as the heir, but on Jeju Island, the inheritance divided up the land amongst all of the sons from the family. Naturally, parental concern was paramount for those children who were due to inherit down with much smaller size arable land on Jeju Island. Each child's living in this barren environment depended on their forefathers' inheritance system, and consequent of this issue many old pictures of the island show off the smallest arable land size. Most daughters were also given a minimum plot of land from which to live and survive off. Again, different from the practice on the Korean Peninsula, some daughters can also be included as the heirs of the family on Jeju Island. As a result, this practice has been one of their cultural foundations of "equality" in Jeju's agri-culture. People call it as "Suneuleum", meaning chip-in help or extend help for others.

With the stone walls around the dry-fields, farmers were able to produce vegetables including carrot, potato, garlic, radish, cabbage, barley, mugwort, buckwheat, and others, but not rice. The cultivated fields are relatively small and come in all sorts of shapes reflecting the cultural backdrop. Because of the field size and shape, no machinery was adapted in Jeju agriculture, hence they could produce the most organic crops in the best natural condition. With that background history of Jeju agriculture, Jeju agro-products and diet are recognized to be most healthy now.

\subsection{New Movements for Agro-Cultural Trials in Jeju Island}

Jeju's multi designations of UNESCO value could be discussed for various reasons. Jeju Island currently honors five UNESCO values and recognitions which are listed in Section 3.1. The local government of Jeju has devoted its full capacity to promoting Jeju's environment, culture, and landscape values throughout the world earlier even before it gained its first UNESCO title in 2002. Since then, the resident islanders have been supportive and gradually recognized the value of UNESCO titles. Jeju is often referred to as the only multi UNESCO titles region, and many visitors also state that. Such situations might impinge positively on islanders' way of thinking or their identities.

Recently, The Batdam Agro-Culture Research Team of the Research Institute for Regional Government and Economy of Korea (Korea RG \& E) in Jeju has published a couple of books on Jeju Batdam Agro-stories focused on Jeju's agro-culture and dynamics of culture. Since the designation of Jeju Batdam Agricultural Heritage System, many farmers' family stories, histories, cultures and community activities along with their concerns and the role of Batdam for the future have been interviewed by various local news media. One of the local's worries is the fading of traditional culture due to upcoming developments which result in a loss of small local farmlands that used to sustain ordinary farmers' lives and their associated stories. It is further felt that the memories, Agro-stories and culture of the farmers in earlier generations must be recorded and shared for the benefit of future generations. 
GIAHS' Jeju Batdam Agricultural Heritage System was also presented during the Gil Exhibitions (Gil means a road or path in Korean) in Jeju in October 2017, where many visitors and residents of Jeju Island attended. The outcome was deemed successful, as more than five hundred visitors stopped by the Jeju GIAHS desk, and about a hundred participants joined the field trip. Most participants showed great interest in getting to know how local people survived the given harsh living environment, and how their culture was suiting their needs in the old days. Participants were invited for walking and exploring with researchers along the segment of Batdam as a field trip, introduced to the variation of Jeju crops, history of trading rice with their vegetables, and the stories of the birth and functions of Batdam. Following the participants' positive responses and remarks for the content of GIAHS Batdam, the research team has decided to expand and develop further Agro-stories around Batdam all over Jeju Island in the near future.

\section{Cultural Management in China}

\subsection{Cultural Problems in Chinese GIAHS}

China was one of the first countries that responded and actively participated in the protection of agricultural heritages. In 2005, Qingtian Rice-Fish Culture System in Zhejiang Province was launched as the first GIAHS in China, which officially begins the conservation of agricultural heritage systems in the country. After more than a decade of exploration and practice, China's agricultural heritage designation and conservation has achieved fruitful results. As of October 2017, China's GIAHS sites rank first in the world with 11 out of the global total of 39 GIAHS sties. In addition, China also established a China Nationally Important Agricultural Heritage Systems (China NIAHS) project to conserve the agricultural heritage at the national level, which now has 91 sites on that list. The overall goal of the GIAHS and China NIAHS program is to identify and safeguard GIAHS sites and their associated landscapes, agricultural biodiversity, knowledge systems and culture.

Culture is a significant part of GIAHS sites, as mentioned in Section 1.2, which is one of the main differences between traditional and modern agriculture. Culture, including values, traditions, behaviors, relationship, etc., has played an important role in maintaining the order of agricultural activities, adjusting interpersonal relationships and the relationship between human and nature. Most of the GIAHS sites in China are located at economically limited and ecologically fragile areas, some of them were even isolated from the outside for hundreds of years, but with well-preserved unique farming methods and traditional cultures. This is particularly the case in regions with significant ethnic-minority populations. However, after being designated as GIAHS sites, the agricultural heritage systems and the related rural area have also been acknowledged worldwide.

Although the study of GIAHS has received great enthusiasm and support from related governmental departments and research institutions, agricultural heritage is still a new concept with a lot of gaps needing to be filled, especially in the field of cultural studies. The previous study of GIAHS was mainly concentrated on the "nature" aspect: biodiversity, ecology, ecosystem services, climate change, etc. Indeed, culture was mentioned, but mostly connected to the studies regarding tourism potential and development. The true value of culture in GIAHS has been underestimated and the cultural related problems during the GIAHS conservation progress have been ignored. Section 4 discusses some cultural related problems that happened in the GIAHS sites in China.

\subsection{The Effects of Tourism on Ethnic Culture at GIAHS Sites}

Although we follow the concept of culture from UNESCO ICH in Section 1.2, culture can also be defined as a way of life and a system of values and beliefs which is a creative, recreational practice [20]. It can be conceptualized at various levels including national and sub-national, incorporating groups such as ethnic peoples [21]. Ethnic means very strongly bounded homogenous cultural identities, firmly associated with a particular homeland and rooted in strong kinship ties, sometimes equal to people whose common physical characteristics are believed to make them socially distinct [21-23]. Ethnicity 
and its associated cultural manifestations are major tourism assets and are often marketing themes for many cultural and agri-cultural heritage sites [24]. However, in most situations, the excessive commercialization threatens the authenticity and sustainable development of the destinations.

Tourism gradually becomes the fastest growing and most profitable industry in many rural areas, also in China, which provides opportunities for economic development and enables interaction between local people with outsiders. In the rush to develop their local tourism industries, many local government authorities at the GIAHS sites, especially in the economically challenged areas, are now actively developing their tangible and intangible cultural assets as a means of developing comparative advantages in an increasingly competitive tourism marketplace [24]. Nevertheless, the dramatic development of tourism can also cause irreversible damage to the indigenous culture [25]. In the face of globalization, the uncontrolled tourism development at unprepared places can cause irreversible deterioration of their native culture, natural environment and local society.

Indeed, many of the GIAHS and China-NIAHS sites are located in the minority areas, such as Congjiang Dong's Rice-Fish-Duck System created by Dong people and Honghe Hani Rice Terraces Systems created by Hani people. Dong and Hani ethnic groups are two of the 56 ethnic groups officially recognized by China, who mostly live in Guizhou, Hunan, Yunnan and Guangxi Province in China. The ethnic culture and unique traditional farming methods provide strong cultural identities to these sites, which made them important actual or potential tourism attractions. With the strong cultural characteristics, some of these places and some of the cultural activities in the places have also been designated as World Cultural Heritage (WCH) and Intangible Cultural Heritage (ICH). For example, the Honghe Hani Rice Terraces System is both a GIAHS site designated by FAO and a listed WCH by UNESCO; the Grand Song of Dong Ethnic Group has been inscribed as an ICH in 2009. Hence, culture, especially ethnic culture, in GIAHS sites should be given more attention and it is necessary to point out a connection between the conservation of cultural heritage (both tangible and intangible) and agri-cultural heritage.

Because of political sensitivities, many poor ethnic-minority areas in China were not fully open to visitors until 1994 [26]. In these areas, tourism may also be employed for purposes of social and political control by regimes intent on asserting "one central culture and its values" or accommodating "peripheral cultures with a dominant core" [21,27]. In addition, ethnical culture can be over-commercialized during tourism development when they are treated as commodities to be bought and sold (Figure 5). Therefore, the authentic is replaced by the contrived and artificial and host cultures, and ethnic cultural experiences are ultimately devalued.

These problems not only exist in cultural heritage sites, but also in agri-cultural heritage GIAHS sites, which include rich farming culture, cultural beliefs and traditional lifestyles. As mentioned before, many of the agricultural heritage sites used to be economically backward and ethnic-minority areas. Tourism aims to be a force fostering economic development by causing less ecological damage. However, tourism has linked local's cultural assets to commercial objectives and was dictated by preconceptions of what visitors wanted to see [28]. Together with the dominating of Han Chinese culture, the sustainability of ethnic culture is being threatened, which will indeed influence the sustainable development of agri-cultural heritage systems.

The Grand Song of Dong Ethnic Group was inscribed on the Representative List of the Intangible Cultural heritage of Humanity in 2009. A popular saying among Dong people is that "Rice nourished the body and songs nourish the soul" [29]. The songs express life philosophy and production knowledge. Indeed, the growing of rice and passing on culture and knowledge in music are very important for Dong people's daily life. Traditionally, Grand Songs are performed formally in the drum-tower, the landmark venue for rituals, entertainment and meetings in a Dong village, or more spontaneously in homes or public places. However, nowadays, Grand Songs are performed widely, regardless of location and occasion, mainly to meet the needs of tourists. As many other cultural traditions, the Grand Songs are losing their authentic and sacred meanings. 


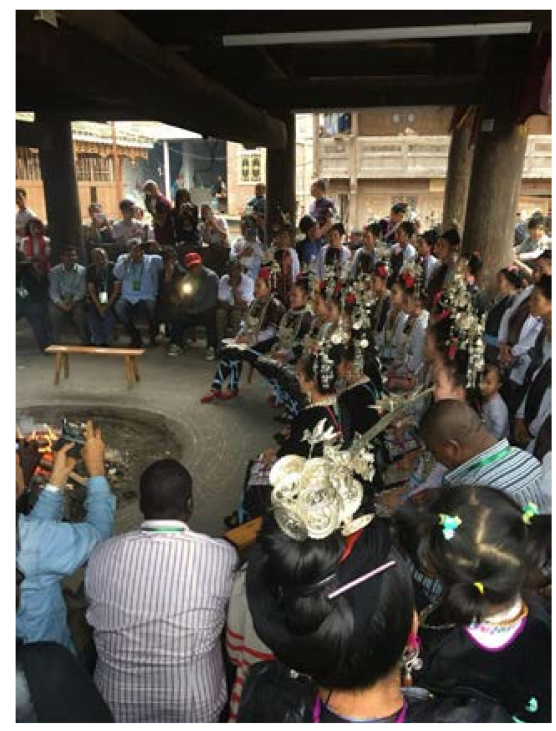

Figure 5. Congjiang Dong women sing Dong Grand Songs for foreign tourists, which were only performed during festivals.

\subsection{Changing of Cultural Identity}

Based on the physical site scale in landscape study, identities have been introduced as: national identity, regional identity, urban identity and local identity. Among them, local identity focuses on people who participate in a very narrative scale of area and how people interact with the local environment [30]. Being designated as a heritage can provide a platform through which identity can be managed, represented, and rebuilt [28-32]. In such situations, a heritage generates a sense of identity, belonging, and public memories among local residents through the production of heritage sites and goods [33], which may "help sustain the ongoing production of local identities" [30].

However, residents are not solely in control of (re)building their new identity [34]. Their identity also depends on how outsiders and other entities perceive of them. The notion that identity change can be imposed by outside forces and occurs beyond the control of local residents was prevalent in early studies [35-37]. These scholars highlighted how outsiders brought western ideology, values, and markets to the underdeveloped world, leading to commodification and/or impoverishment of local history and cultures [38].

Since they were isolated from the outside for quite a long time, unity and coherence among the agri-cultural heritage sites has been a key factor regarding collective living and development [39]. Through communications with each other, people's emotions become a more common emotion and a more unified identity gradually evolves. Being designated as GIAHS or China-NIAHS sites has put the destinations in front of the world, which has brought significant social, economic, and environmental transformations to the local community. Tourists, investors, researchers and people from all around the world convey modernization, new ideas and fast development to the places. However, the "developmental" factors may give rise to identity change. Such a context renders new insight to the mechanisms by which agri-cultural heritage systems may alter residents' identity.

Rural areas tend to have a longer memory than cities, due to their more extensive historical and cultural linkages. Chinese culture has traditionally been agriculture-based. Without rural culture, we lose our grounding, history, and diversity. These things not only foster artistic wellbeing, but also intellectual and political independence. Perhaps the central government might neglect the debilitating effect this centralization has on their culture. Protecting and restoring the culture of agri-cultural heritage systems can bring residents a sense of pride and identity, and in turn promote creativity and growth. 
Therefore, culture of the GIAHS systems should not only be considered as tourism assets or additional products/information of the agri-cultural heritage systems. While preserving the agricultural heritage systems, the traditional culture should also be cherished and protected as an important part of the system. In addition, culture is closely related to the forming of rural identity of the residents at the agricultural heritage systems. If we say the agricultural system, landscapes, and the ecological system are the body of the agricultural heritage system, the culture, knowledge and rural identity are the soul. However, under the pressure of tourism development and globalization, the conservation of the unique culture and identity of many GIAHS systems are being threatened. Thus, it is necessary to advise the GIAHS experts and scholars to pay more attention on the culture aspect of the GIAHS systems, rather than only focus on the agricultural aspect.

\section{Conclusions}

In each section, we describe the current situations of GIAHS in Japan, Korea, and China. China has the longest history and engagement with the program, lasting over twelve years, since 2005. Japan has half of the history of China's connection, going back six years, since 2011, while Korea has the most recent connection, covering the three years, since 2014. Although these three East Asian nations have a common base of agriculture with an underlying reliance on rice farming, each country is aware of their different stages and of their own cultural concerns around agriculture today. Here, we find some common cultural problems and prospects through their systems of management (Table 2).

Table 2. Cultural problems and prospects in East Asian GIAHS.

\begin{tabular}{ccc}
\hline Problems & Prospects & Sections * \\
\hline Definition & To establish own definition of culture in GIAHS & 1.2 \\
Role & To show the role of culture in GIAHS clearly & 1.2 \\
Listing & To make each list and compare them & 2.1 \\
Agrostory & To combine contents and edit a related story & $2.2,3.3$ \\
Tourism & To establish GIAHS tourism and compare the data & $3.3,4.2$ \\
Identity & To deal with new issues as ethnicity or commercialization & $4.2,4.3$ \\
Comparison & To compare what we are similar and not similar & 5 \\
Globalization & To create a platform to discuss our cultural matters & 5 \\
\hline & * Sections that discussed in this paper.
\end{tabular}

In this paper, we focus upon one of the more neglected criterion of GIAHS, "Cultures, Value Systems and Social Organizations", among the five criteria. At the same time, we use for our discussions the more clearly defined classification of cultural expressions that are brought by the UNESCO ICH program. However, GIAHS also has to build their own definition and this should be the first task in this field. The case studies in this paper also show GIAHS must more clearly outline the role of culture in this context. Thus far, we show only the examples of Japan, as seen in Figures 1-3, but how about Korea or China? They also may experiment with similar research and methods for an opportunity to compare results. Moreover, the data, methods used, or analytic techniques we take should be examined more. For example, the data indicated in Figures 2 and 3 are gathered from Instagram; however this social media platform is not accessible in China now, where instead they rely upon applications such as Weibo or MeituXiuXiu. The discussion around which analytic methods would be more useful to compare among Asian countries is clearly needed; in particular can comparative data be assessed where there is no common social media platform?

Table 1 is the first attempt to combine the list of GIAHS sites and Japanese Cultural Properties together with the forms of cultural heritage we can see in the GIAHS sites. However, it does not mean that all cultural properties are in turn associated directly with the agricultural heritage systems; they are now just sited in the same locations. Although each Japanese GIAHS site has compiled their own lists, this is as far as research has thus far evolved. There is a need to discuss why and how cultural 
properties are linked to the agricultural system. Moreover, of course, not only in Japan but in China and Korea there is a need to consider lists comparatively, and analyze which cultural aspects should still be included and which ones omitted from the GIAHS system.

To show the relationship between cultural properties and agricultural systems, this paper suggested the concept of "Agrostory" as introduced in Section 2.2. On this viewpoint, Korea has much progressed and is now planning GIAHS tourism eagerly, for example as demonstrated in the Gil Exhibition mentioned in Section 3.3, which has informed visitors about the relationship between cultural properties and the agricultural system. Hence, many Koreans can understand gradually the importance to conserve their agricultural heritage systems and, on the other hand, many farmers are also recognizing gradually the meaning of utilizing world titles such as FAO GIAHS or UNESCO Global Geoparks.

Such world titles were the honorable results for the local people at first; however, if they mistake the means for the end, it will take on new problems as indicated in the section concerning Chinese GIAHS. Being a site of world designations and changing their original forms or meanings to perform for visitors sometimes brings about identity changes, altering their essential aspects and de-contextualizing their meanings. A similar issue will reliably happen even in Korea or Japan soon. Some cultural anthropologists and folklorists have already pointed out this issue and termed it folklorismus or folklorization [40], where people begin to utilize their traditional ethnic/folkloric culture but in different and removed contexts to the original. The grouping in this paper also shares the concerns of scientific or disciplinary abuses. For instance, if you always force agriculture to explain every culture, it might fall into the category of Environmental Determinism that cultural geographers had argued against for a long time [41]. If you set up any cultural steps of development or superiority and inferiority of culture, of course, it also falls into the old-fashioned familiar term of "Social Evolutionism" [42]. Cultural Anthropologists fought against such attitude or consideration and finally established the concept of Cultural Relativism [43]. However, now, the behavior of selecting a specific culture from many other cultures as a designated heritage means to discover superiority or inferiority of culture again.

For such new issues emerging out of the processes of globalization, we should set up a common platform to discuss each other's experiences. Such a platform would have two principle roles: one is for the discussion of positive matters, the other is for the negative ones. In the negative discussion, we have to solve the issues as our common matters that we will face now and the future. Although we already discussed some issues of identity or commercialism above, we still have many other issues. For example, some might criticize the idea of an Agrostory for stuffing cultural diversity into only one story. For such criticism, arguments pointing to the construction of a Geonarrative, instead of a Geostory, among the Geopark networks will be a useful experience to draw from [15].

In the positive discussion, we can deal with the differences or similarity through comparative studies. Whether the traditional cuisine can be a cultural property, for example, is an interesting cultural issue. In China, we can find abundant Chinese foods and cooking ways are designated as the ICH of China, however, there are currently only a few in Korea with the designation of special palace cuisine or brewing traditional alcohol, and no examples in Japan. On the other hand, Korea and Japan have UNESCO ICH of food (Both of 'Kimjang, making and sharing kimchi in the Republic of Korea' and 'Washoku, traditional dietary cultures of the Japanese, notably for the celebration of New Year' were designated as ICH in 2013 by UNESCO) but China does not at all. The discussion about these matters in GIAHS can give some effective suggestions to the discussions on UNESCO in turn. China, Japan and Korea have a lot of common culture such as tea planting or women divers, as introduced in Sections 2.1 and 3.1. Some members are already searching for a way to cooperate transnationally with their common agricultural products (for instance, Shizuoka GIAHS held an international forum of tea in May of 2016 and also invited people concerned with Chinese and Korean GIAHS of tea). Tea is one of them and we surely can make comparative research on sites that have tea industries such as Fujian GIAHS of Jasmine oolong tea in China, Shizuoka GIAHS of green tea in Japan, or Hadong 
GIAHS of green tea of Korea. Women divers are also common cultural features of both Korea and Japan, and UNESCO ICH in Jeju GIAHS, also an important cultural property in Noto GIAHS in Japan. In this paper, we point out our eight common cultural problems and prospects, the discussions of such specific cultural theme in each GIAHS will need to be deepened further from now.

Acknowledgments: This research was financially supported by Technical Support of China-Globally Important Agricultural Heritage System Conservation Program by Ministry of Agriculture and Rural Affairs of China. In the 4th ERAHS conference held in Huzhou city in China on 12 July 2017, a symposium called "Innovate Mechanisms for the Inheritance of Traditional Culture" was convened, and seven speakers, including the authors of this paper, presented there. This paper is based on the discussion. Some parts of this paper received a grant from Oita Prefectural Government of Japan, Kyushu University, and Institute of Geographic Sciences and Natural Resources Research, Chinese Academy of Sciences (IGSNRR), during 2016-2017. Especially, we would like to express our gratitude to Mitsuyasu Yabe and Hisako Nomura of Kyushu University; Wenjun Jiao of IGSNRR, Iching Chen of the Museum of Memories, Tainan; and Jonathan Karkut of TouchTD, London.

Author Contributions: Hiroyuki Kajihara and Su Zhang conceived and designed the research. Hiroyuki Kajihara wrote the Introduction, Cultural management in Japan, and Conclusions. Wonhee You wrote Cultural management in Korea. Su Zhang and Qingwen Min wrote Cultural management in China. All the editors read and edited the manuscript and approved the final version.

Conflicts of Interest: The authors declare no conflict of interest.

\section{References}

1. FAO. GIAHS around the World. Available online: http://www.fao.org/giahs/giahsaroundtheworld/en/ (accessed on 7 December 2017).

2. FAO. Selection Criteria and Action Plan. Available online: http://www.fao.org/giahs/become-a-giahs/ selection-criteria-and-action-plan/en/\#c367916 (accessed on 7 December 2017).

3. FAO. Goal and Objectives. Available online: http://www.fao.org/giahs/background/goal-and-objectives / en/ (accessed on 7 December 2017).

4. UNESCO. What is Intangible Cultural Heritage? Available online: https://ich.unesco.org/en/what-isintangible-heritage-00003 (accessed on 7 December 2017).

5. Japan Marketing Cooporation. Available online: https://www.tourism.jp/wp/wp-content/uploads/2014/ 03/research_140331_japan-guide.pdf (accessed on 11 July 2017).

6. Shizuoka GIAHS Has no Pages Regarding Culture. Available online: https://www.chagusaba.jp/english/ index.html (accessed on 19 March 2018).

7. Minabe GIAHS. Available online: https://www.giahs-minabetanabe.jp/ume-system/ (accessed on 6 December 2017).

8. Takachiho GIAHS. Available online: http://takachihogo-shiibayama-giahs.com/about (accessed on 6 December 2017).

9. Noto GIAHS. Available online: http://www.pref.ishikawa.jp/satoyama/noto-giahs/lib_bunka.html (accessed on 6 December 2017).

10. Kunisaki GIAHS. Available online: http://www.kunisaki-usa-giahs.com/about_giahs/culture.html (accessed on 6 December 2017).

11. Aso GIAHS. Available online: http:/ / www.giahs-aso.jp/value/culture_agriculture (accessed on 6 December 2017).

12. Nagara GIAHS. Available online: http://giahs-ayu.jp/kurashi (accessed on 6 December 2017).

13. Kajihara, H. Geoparks and the Role of Geography: Comparison with Similar Institutions. E-J. GEO 2014, 9, $61-72$.

14. What is a Geopark? Available online: http://www.europeangeoparks.org/?page_id=165 (accessed on 7 December 2017).

15. Yuhora, K.; Niina, A.; Kajihara, H.; Mokudai, K. The Role of Geographical Perspective in the Development of Geoparks. E-J. GEO 2014, 9, 13-25.

16. Matsukawa, M.; Obata, I. Santonian fossils from the upper Cretaceous Atokura Formation in Kwanto Mountains, Japan, and their significances. Bull. Tokyo Gakugei Univ. Div. Nat. Sci. 2012, 64, 143-152.

17. KIAHS. Available online: http:/ / www.mafra.go.kr/main.jsp (accessed on 30 November 2017). 
18. The Heated Floors: Traditional Ondol. The Korea Times. Available online: http:/ /www.koreatimes.co.kr/ www /news/art/2011/03/273_81782.html (accessed on 6 December 2017).

19. World Natural Heritage 'Jeju-Island'. MNC 2017. Available online: http://mnc2017.org/?page_id=53 (accessed on 30 November 2017).

20. King, A. Culture, Globalization and the World-System: Contemporary Conditions for the Representation of Identity; Macmillan: London, UK, 1991.

21. Henderson, J.; Teck, G.K.; Ng, D.; Tan, S.R. Tourism in ethnic communities: Two Miao villages in China. Int. J. Herit. Stud. 2009, 15, 529-539. [CrossRef]

22. Applebaum, R.P.; Chamblis, W.J. Sociology: A Brief Introduction; Longman: New York, NY, USA, 1997.

23. Hall, S. New cultures for old. In A Place in the World?: Places, Cultures and Globalization; Massey, D., Jess, P., Open University, Eds.; Oxford University Press: Oxford, UK, 1995.

24. OECD. The Impact of Culture on Tourism; OECD Publishing: Paris, France, 2009.

25. UNESCO. Impact: The Effects of Tourism on Culture and the Environment in Asia and the Pacific: Cultural Tourism and Heritage Management in the World Heritage Site of the Ancient Town of Hoi An, Viet Nam, Bangkok. UNESCO, 2008. Available online: http://unesdoc.unesco.org/images/0018/001826/182646e.pdf (accessed on 30 October 2017).

26. Hillman, B. The rise of the community in rural China: Village politics, cultural identity and religious revival in a Hui hamlet. China J. 2004, 51, 53-73. [CrossRef]

27. Gradburn, N. Tourism and cultural development in East Asia and Oceania. In Tourism and Cultural Development in Asia and Oceania; Yamashita, S., Din, K.H., Eades, J.S., Eds.; University Kebangsaam: Kula Lumpur, Malaysia, 1997.

28. Rogers, S.C. Which heritage? Nature, culture, and identity in French rural tourism. French Hist. Stud. 2002, 25, 475-503. [CrossRef]

29. UNESCO. Grand Song of the Dong Ethnic Group. Available online: https://ich.unesco.org/en/RL/grandsong-of-the-dong-ethnic-group-00202 (accessed on 4 December 2017).

30. Shao, Y.H.; Liu, B.Y. Losing of local identity in rapid developing China. In Proceedings of the 2nd Annual International Conference on Social Science and Contemporary Humanity Development, Wuhan, China, 15-17 July 2016; pp. 163-168.

31. Jeong, S.; Santos, C.A. Cultural politics and contested place identity. Ann. Tour. Res. 2004, 31, 640-656. [CrossRef]

32. Santos, C.A.; Yan, G. Representational politics in Chinatown: The ethnic other. Ann. Tour. Res. 2008, 35, 879-899. [CrossRef]

33. Waitt, G.; McGuirk, P.M. Making time: Tourism and heritage representation at millers point, Sydney. Aust. Geogr. 1996, 27, 11-19. [CrossRef]

34. Xue, L.; Kerstetter, D.; Hunt, C. Tourism development and changing rural identity in China. Ann. Tour. Res. 2017, 66, 170-182. [CrossRef]

35. Lanfant, M.F.; Allcock, J.B.; Bruner, E.M. International tourism, internationalization and the challenge to identity. In International Tourism: Identity and Change; Bruner, E.M., Ed.; Sage: London, UK, 1995.

36. Nunez, T.A. Tourism, tradition, and acculturation: Weekendismo in a Mexican village. Ethnology 1963, 2, 347-352. [CrossRef]

37. Shepherd, R. Commodification, culture and tourism. Tour. Stud. 2002, 2, 183-201. [CrossRef]

38. Medina, L.K. Commoditizing culture: Tourism and Maya identity. Ann. Tour. Res. 2003, 30, $353-368$. [CrossRef]

39. Wang, X.Y. A case study of Miao village in China: Cultural identity, change and conservation. Adv. Anthropol. 2015, 5, 126-135. [CrossRef]

40. Bausinger, H. Volkskultur in der Technischen Welt; Kohlhammer: Stuttgart, Germany, 1961.

41. de la Blache, P.V. Principes de Géographie Humaine; ENS Éditions: Paris, France, 1922.

42. Morgan, L.H. Ancient Society; Henry Holt and Company: New York, NY, USA, 1877.

43. Boas, F.; Stocking, G.W. (Eds.) A Franz Boas Reader; University of Chicago Press: Chicago, IL, USA, 1974.

(C) 2018 by the authors. Licensee MDPI, Basel, Switzerland. This article is an open access article distributed under the terms and conditions of the Creative Commons Attribution (CC BY) license (http:/ / creativecommons.org/licenses/by/4.0/). 